\title{
Suscetibilidade do cedro ao ataque de pragas em Floresta Estacional Decidual
}

\author{
Lílian Daniel Pereira( ${ }^{(1)}$, Frederico Dimas Fleig( ${ }^{(1)}$, Evandro Alcir Meyer(1), \\ Karina Lanzarin ${ }^{(1)}$ e Karina Wolf ${ }^{(1)}$
}

(1)Universidade Federal de Santa Maria, Laboratório de Manejo Florestal, Prédio 44B, CEP 97105-900 Santa Maria, RS, Brasil. E-mail: liliandapereira@yahoo.com.br, dimasfleig@uol.com.br, eam.meyer@gmail.com, karinalanzarin@gmail.com, karina-mw@hotmail.com

Resumo - O objetivo deste trabalho foi avaliar as características das plantas de cedro (Cedrela fissilis) atacadas por pragas, os danos causados e as condições em que estes foram mais pronunciados. Realizou-se um censo dos indivíduos de cedro por caminhamento em uma área total de 5,55 ha de floresta nativa, no município de Silveira Martins, RS. Cedros com altura total superior a $15 \mathrm{~cm}$ e diâmetro do coleto inferior a $12 \mathrm{~cm}$ foram medidos, e foi avaliado seu estado fitossanitário em relação às pragas. Foram confeccionados histogramas de frequência de diâmetro do coleto, e analisou-se a relação hipsométrica das árvores atacadas e sadias por meio da análise de covariância. Para a análise espacial dos indivíduos, foram feitos mapas de densidade de cedros e mapas de taxa de risco do serrador e da mariposa. As árvores com maior probabilidade de ataque foram aquelas com diâmetro de coleto entre 2 e $6 \mathrm{~cm}$. As clareiras ou áreas com baixa densidade total de árvores foram as áreas mais suscetíveis aos ataques da lagarta Hypsipyla grandella, e locais com elevada densidade de indivíduos cujo diâmetro de coleto mede entre 8 e $12 \mathrm{~cm}$ são os mais suscetíveis ao ataque de larvas do Oncideres sp.

Termos para indexação: Cedrela fissilis, Hypsipyla grandella, Oncideres, mariposa, serrador.

\section{Susceptibility of cedar to pest attack in seasonally deciduous forest}

\begin{abstract}
The objective of this work was to evaluate the characteristics of cedar plants (Cedrela fissilis) attacked by pests, the resultant damages, and the conditions in which the damage was more pronounced. A census of cedar individuals was conducted by going through a total area of 5.55 hectares of native forest in the municipality of Silveira Martins, in the state of Rio Grande do Sul, Brazil. Cedars with total height greater than $15 \mathrm{~cm}$ and collar diameter less than $12 \mathrm{~cm}$ were measured, and their pest status was evaluated. Frequency histograms of the collar diameter were made, and the hypsometric relationship of attacked and healthy trees was evaluated by analysis of covariance. For the spatial analysis of individuals, maps of cedar density and maps for risk assessment of sawyer beetle and moth were made. Trees with the greatest probability of being attacked were those with collar diameter between 2 and $6 \mathrm{~cm}$. The clearings and areas with low total density of trees were the most susceptible ones to attacks of the Hypsipyla grandella caterpillar, and locations with high density of individuals whose collar diameter is between 8 and $12 \mathrm{~cm}$ are the most susceptible ones to the attacks of Oncideres sp. larvae.
\end{abstract}

Index terms: Cedrela fissilis, Hypsipyla grandella, Oncideres, moth, sawyer beetle.

\section{Introdução}

O cedro, Cedrela fissilis Vell, é uma espécie promissora para os reflorestamentos comerciais; contudo, estes podem ser inviabilizados em razão de danos causados pela lagarta Hypsipyla grandella Zell. (Lepidoptera: Pyralidae), a broca-do-cedro (Penã-Ramírez et al., 2011), provavelmente atraída por componentes orgânicos voláteis (Abraham et al., 2014), que ataca principalmente as gemas apicais das plantas (Reitz et al., 1983).
O principal dano causado por essa lagarta é a destruição do broto terminal de plântulas e indivíduos jovens em razão da escavação de galerias na medula, o que desencadeia, na planta, a emissão de brotações que prejudicam a forma retilínea do tronco e o crescimento em altura (Lunz et al., 2009), gerando troncos extremamente deformados (Howard \& Merida, 2015). O controle desses danos é extremamente difícil, pois apenas uma lagarta pode causar danos ao ramo terminal (Hilje \& Cornelius, 2001; Howard \& Merida, 2015). Além disso, entre os vários estudos sobre o controle 
dessa praga, todos indicam que nenhuma técnica isolada tem sido satisfatória para o combate (Lunz et al., 2009).

Outra praga relacionada ao cedro, com ocorrência em pequena escala, é o serrador Oncideres sp. (Coleoptera: Cerambycidae) (Reitz et al., 1983), conhecido pelo ataque em plantações de Acacia mearnsii de Wild (O. impluviata; O. dejeani Thoms). O dano causado por esse inseto é realizado pelas fêmeas, que anelam galhos ou troncos para depositar seus ovos (Costa et al., 2011). Apesar de pouco relacionada ao cedro e em razão da escassez de relatos e artigos que se refiram à ocorrência dessa praga na espécie, esse gênero tem ganhado destaque, pois diversos estudos têm relatado a sua incidência em espécies distintas (Lemes et al., 2011; Souza et al., 2012; Witeck Neto et al., 2013).

Para o manejo de pragas, é necessário o conhecimento sobre o período crítico em que a planta é atacada, bem como das condições em que o ataque ocorre, pois essas informações podem auxiliar na elaboração de estratégias que subsidiem o controle dos insetos. Atualmente, não existem estratégias para controlar a incidência de ataques da lagarta $H$. grandella (Lunz et al., 2009). Algumas tentativas com o controle biológico, apesar de serem promissoras, não têm sido eficazes (Pinto et al., 2014), e as adubações com potássio (Calixto et al., 2015) e cálcio e boro também têm sido alternativas estudadas (Silva Junior et al., 2014).

O objetivo deste trabalho foi avaliar os parâmetros biométricos das plantas de cedro (Cedrela fissilis) atacadas, os danos causados pelos insetos e em quais condições as incidências de ataques são mais intensas.

\section{Material e Métodos}

O estudo foi realizado no período de setembro de 2013 a janeiro de 2014, na localidade de Val Feltrina, no município de Silveira Martins, RS, Brasil. O ponto central situou-se entre as coordenadas UTM 6719650S e $246650 \mathrm{E}$ da zona SH22. A formação florestal nativa da região foi classificada como Floresta Estacional Decidual (Instituto Brasileiro de Geografia e Estatística, 2004).

O clima dessa região é do tipo Cfa, subtropical úmido, sem estação seca definida e com verões quentes, conforme a classificação de Köppen. A temperatura média anual é de $19^{\circ} \mathrm{C}$, a temperatura média do mês mais quente é superior a $22^{\circ} \mathrm{C}$, a temperatura média do mês mais frio é superior a $3^{\circ} \mathrm{C}$, e a precipitação anual média é de $1.769 \mathrm{~mm}$ (Kuinchtner \& Buriol, 2001). O solo predominante na região é o Neossolo Litólico húmico típico (Santos et al., 2006).

Um censo das árvores de cedro foi realizado por meio de caminhamento em uma área total de 5,55 hectares. A área apresentou transições de floresta em estágio de regeneração inicial a regeneração intermediária, com algumas manchas de florestas maduras em locais com elevada declividade e instabilidade do terreno, o que determinou a forma irregular da área amostrada (Figura 1). Como a floresta apresenta variações quanto ao estágio de regeneração, a área foi dividida em quatro categorias: A, B, C e D. A área A, com 0,36 hectare, foi caracterizada pelo uso mais intenso de solo e pela menor densidade total de árvores, com afloramentos rochosos; as áreas $\mathrm{B}$, com 0,1 ha, e $\mathrm{C}$, com 0,8 ha, eram clareiras com raio aproximado de 17,5 e $16 \mathrm{~m}$, respectivamente; e D foi a área de regeneração intermediária, com 5,0 hectares. Esta última compunha-se de um mosaico de vegetações com diferentes idades e era formada por áreas de lavoura abandonada, cujo dossel apresentava a altura média de $10 \mathrm{~m}$, e por áreas de vegetação mais velha, com dossel acima de $15 \mathrm{~m}$ (Figura 1).

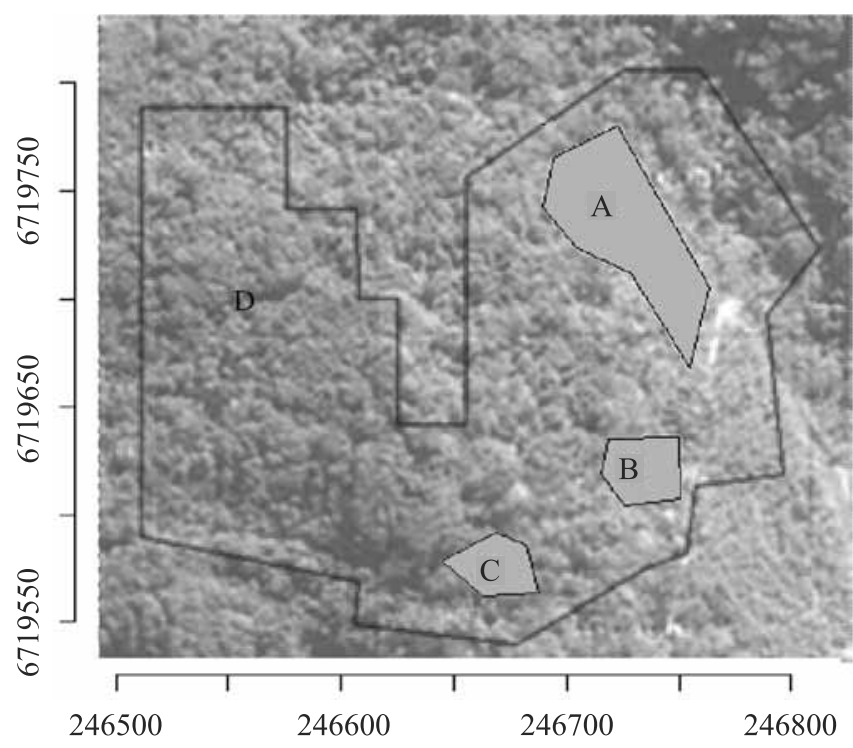

Figura 1. Área de estudo na região de Val Feltrina, município de Silveira Martins, RS, localizado entre as coordenadas UTM 6719650S e 246650E da zona SH 22. Classificação da área em: floresta com uso mais intenso do solo e baixa densidade total de árvores (A); floresta em estágio de regeneração inicial (B e C); e floresta em estágio de regeneração intermediária (D). 
As árvores atacadas foram identificadas por meio da visualização do dano ocasionado pelo ataque das referidas pragas. O limite de amostragem foi delimitado pelo inventário de reconhecimento, que permitiu verificar as dimensões das árvores atacadas. As coordenadas dos cedros com altura total superior a $15 \mathrm{~cm}$ e diâmetro do coleto inferior a $12 \mathrm{~cm}$ foram coletadas com GPS Garmin76CsxMap (Garmin International, Kansas, EUA). A circunferência do coleto e a altura total da planta foram medidas com fita métrica, e o estado fitossanitário foi anotado para determinar quais plantas estavam saudáveis e quais foram atacadas pelo besouro serrador ou pela lagarta. Nos cedros atacados pelo serrador, também foi medida a altura do ataque.

Um histograma de frequência de diâmetro do coleto das árvores sadias e atacadas foi confeccionado. Para a verificação do dano causado pelas pragas, foi ajustado o modelo da altura total (Ht) em função do diâmetro do coleto (DC) (relação hipsométrica) das árvores atacadas e das sadias, por meio da análise de covariância, considerando-se $1 \%$ de probabilidade. As análises foram realizadas com pacote estatístico $\mathrm{R}$ (The R Foundation, 2013).

Mapas de densidade dos cedros foram confeccionados com a função de densidade kernel gaussiana isotrópica e densidade em função do diâmetro do coleto, com a regressão suavizada de kernel ('kernel regressions smoother') (Baddeley \& Turner, 2005). Os mapas de taxa de risco - também denominada de taxa bruta, que corresponde à razão entre o número de eventos ocorridos (ataque da larva do serrador e da lagarta da mariposa) e o número total de plantas expostas à ocorrência - foram feitos por meio da divisão entre a matriz da função densidade do total de indivíduos e a matriz da função densidade dos indivíduos atacados, com largura de banda (bandwidth) de $20 \mathrm{~m}$ (Silva et al., 2011). Os mapas foram construídos com os pacotes estatísticos R (The R Foundation, 2013) e Spatstat (Baddeley \& Turner, 2005).

\section{Resultados e Discussão}

Entre as 206 plantas de cedro avaliadas, $70(34,0 \%)$ foram danificadas pelo ataque da larva do serrador (Figura 2 C), e $55(26,7 \%)$ pela lagarta da mariposa (Figuras $2 \mathrm{~A}$ e B). Ao contrário do esperado, o ataque do serrador foi superior ao da lagarta da mariposa.
Além disso, observou-se a ocorrência de plantas com sinais de danos do ataque da larva do serrador em múltiplas ocasiões. Destas, 18 plantas foram atacadas duas vezes, 2 foram atacadas três vezes, e 1 foi atacada cinco vezes. Além disso, 17 plantas foram atacadas pelas duas pragas. A altura dos cedros atacados pela lagarta variou entre 0,67 e $6,9 \mathrm{~m}$. Foram encontrados dois indivíduos que emitiram mais de uma brotação, o que compromete a qualidade do fuste. Pode-se afirmar que as plantas atacadas pela larva do serrador apresentam claramente deformidades no fuste, com brotações que comprometem a qualidade estética e funcional da planta (Figura $2 \mathrm{D}$ ), principalmente em árvores com elevada altura de ataque.

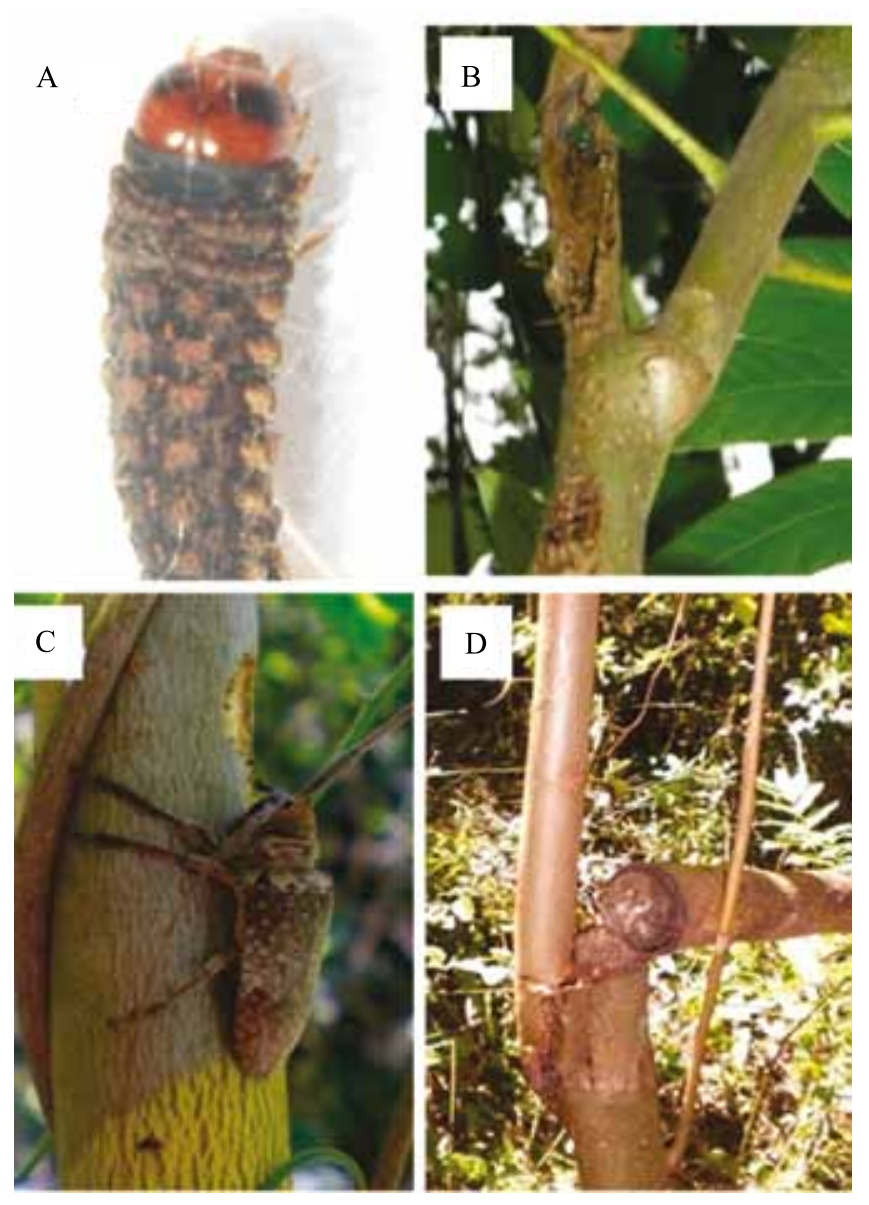

Figura 2. Exemplar da larva de Hypsipyla grandella, encontrada no caule de cedro atacado em 19 de agosto de 2013 (A); ponteira de cedro atacada por Hypsipyla grandella (B); Oncideres sp. encontrado em tronco de cedro no dia 28 de janeiro de 2013 (C); e cedro atacado por Oncideres sp. (D), em Val Feltrina, RS. Créditos: Lílian Daniel Pereira. 
As árvores danificadas pelo ataque do serrador tinham diâmetro do coleto entre 1,6 e $12 \mathrm{~cm}$, e a altura do ataque variou de 0,05 a $3 \mathrm{~m}$, com média de $0,82 \mathrm{~m}$ e desvio-padrão de 0,73 . Os histogramas de frequência indicam a preferência das pragas por árvores com diâmetros de coleto entre 2 e $6 \mathrm{~cm}$ (Figura 3). Poucas plantas com diâmetro do coleto menor que $2 \mathrm{~cm}$ foram atacadas, mesmo com sua elevada frequência, como indicado pelo histograma das árvores saudáveis. Resultado semelhante foi observado por Costa et al. (2013) em plantio de mogno (Swietenia macrophylla King), em que os autores não observaram ataque até 360 dias após plantio, provavelmente em razão da dimensão das plantas que apresentavam diâmetro do coleto igual ou inferior a $2 \mathrm{~cm}$.

É importante notar que os danos causados pelo ataque da lagarta da mariposa diminuem drasticamente em árvores com diâmetro de coleto maior que $6 \mathrm{~cm}$, conforme indicado pelo histograma (Figura 3). Entretanto, como este não representou a percentagem de árvores danificadas, a diminuição de ataque para os diâmetros superiores a $6 \mathrm{~cm}$ pode ser decorrente da baixa frequência de indivíduos a partir dessa classe.

A percentagem de árvores danificadas pelos ataques, por classe de diâmetro, indica que $H$. grandella apresenta preferência por indivíduos cujos diâmetros do coleto são de 10 a $12 \mathrm{~cm}$, além da preferência pelos indivíduos com diâmetros entre 2 e $6 \mathrm{~cm}$. Contudo, a elevada proporção de ataque nas árvores com diâmetro de coleto entre 10 e $12 \mathrm{~cm}$ pode ter sido influenciada pelo baixo número de árvores encontradas com essas dimensões (Figura 4). A altura média correspondente ao diâmetro com maior percentagem de ataque da lagarta $H$. grandella (de $11,5 \mathrm{~cm})$ é de $6 \mathrm{~m}$, e há evidências de que árvores que já alcançaram essa altura apresentam o menor risco de ataque (Hilje \& Cornelius, 2001). Portanto, uma estratégia de controle silvicultural de $H$. grandella é promover um rápido estabelecimento e crescimento, de modo a reduzir a fase de desenvolvimento em que a planta é mais suscetível ao dano. Isso pode ser feito pela seleção de sítios adequados, luz sobre a copa e sombreamento lateral, para promover o crescimento vertical, e poda das plantas atacadas (Yared \& Carpanezzi, 1981).

A percentagem de árvores danificadas pelo ataque do serrador foi maior em indivíduos com diâmetro de coleto entre 4 e $8 \mathrm{~cm}$ (Figura 4). A relação hipsométrica para as árvores saudáveis resultou na equação $\mathrm{Ht}=0,42+0,581 \mathrm{DC}$, em que DC é o diâmetro do coleto, o coeficiente de determinação foi 0,598 , e o erro-padrão foi 1,02. A análise de covariância, para a relação hipsométrica entre as árvores atacadas pelo besouro serrador e as árvores saudáveis, indicou diferença somente quanto à inclinação da regressão $(\mathrm{t}=-6,34, \quad \mathrm{p}<0,01), \quad$ tendo-se mantido o mesmo intercepto $(\mathrm{t}=-0,72, \mathrm{p}=0,47)$ e gerado a equação $\mathrm{Ht}=0,42+0,413 \mathrm{DC}$ (Figura $5 \mathrm{~A}$ ). $\mathrm{O}$ mesmo fato ocorreu nas árvores atacadas pela lagarta da mariposa: a análise de covariância indicou diferença somente quanto à inclinação $(\mathrm{t}=4,73, \mathrm{p}<0,01)$, tendo-se mantido o mesmo intercepto $(\mathrm{t}=0,425, \mathrm{p}=0,65)$, o que resultou na equação $\mathrm{Ht}=0,42+0,413 \mathrm{DC}$ (Figura $5 \mathrm{~B}$ ).

As equações das árvores atacadas foram idênticas e indicaram que o dano aumentou com o aumento da dimensão da árvore. A relação hipsométrica das
A

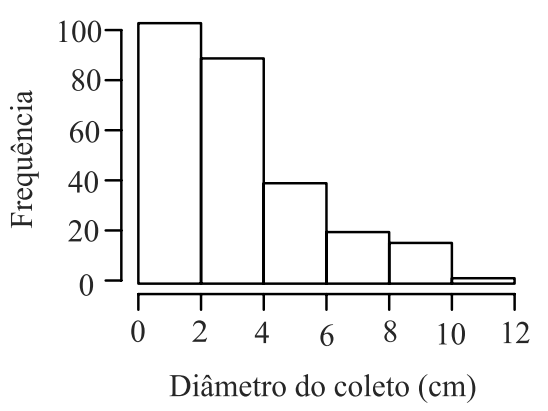

B

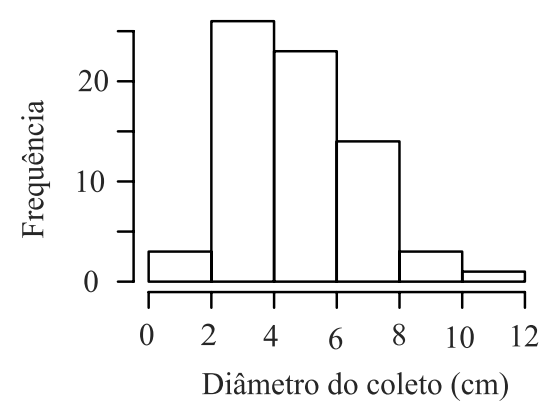

C

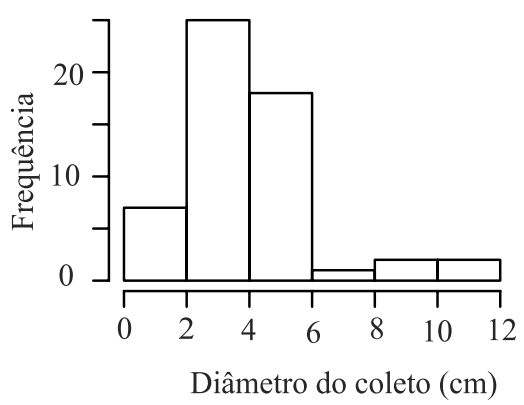

Figura 3. Histograma de frequência do diâmetro do coleto das árvores saudáveis (A), das atacadas pelo serrador (B) e das atacadas pela mariposa (C), na região de Val Feltrina, município de Silveira Martins, RS.

Pesq. agropec. bras., Brasília, v.51, n.5, p.607-614, maio 2016

DOI: $10.1590 / \mathrm{S} 0100-204 X 2016000500022$ 
árvores atacadas pela lagarta mostrou que, apesar de as plantas não apresentarem comprometimento quanto à sua qualidade estética (Grogan et al., 2005; Howard \& Merida, 2015), verificou-se um retardo do desenvolvimento, com redução de altura, em comparação às árvores sadias. Contudo, pôde-se observar que, nas duas categorias de ataques, houve pontos de árvores atacadas que estavam semelhantes aos das sadias, o que indicou restabelecimento dessas

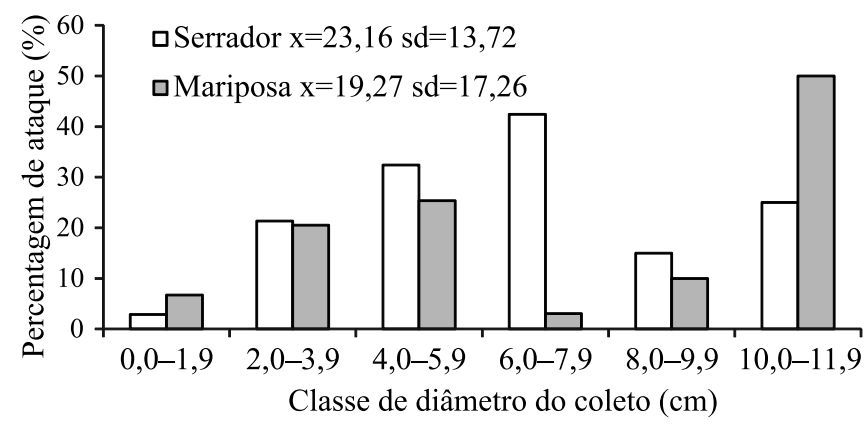

Figura 4. Percentagem de indivíduos de Cedrela fissilis atacados pelo serrador (Oncideres sp.) e pela mariposa $H$. grandella, por classe de diâmetro de coleto, na região de Val Feltrina, município de Silveira Martins, RS.

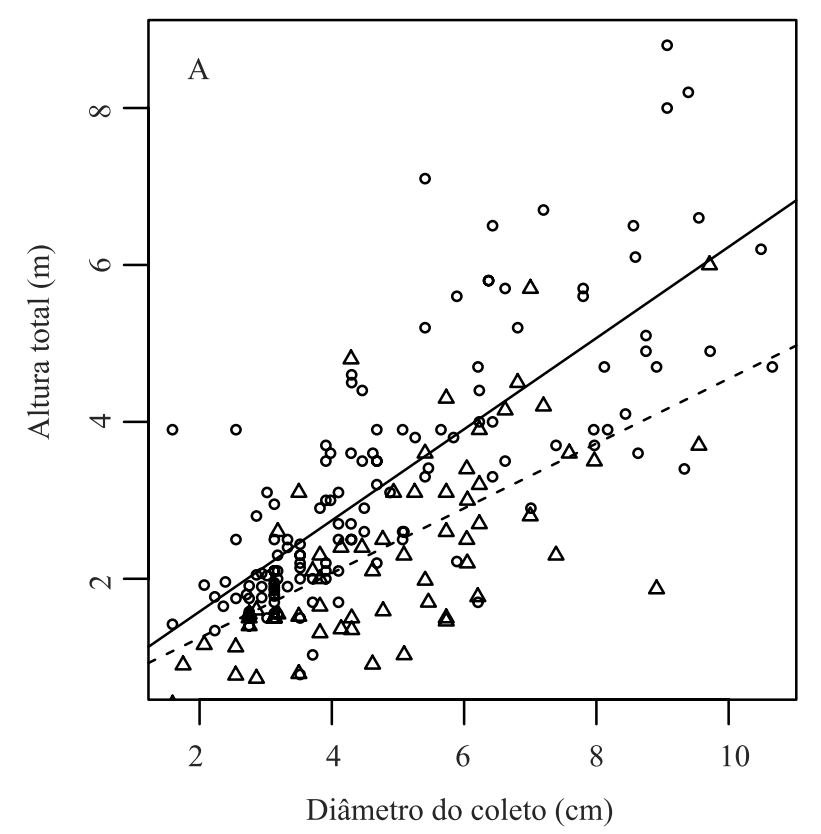

árvores. Entretanto, em alguns casos de árvores atacadas pela larva do besouro, isso ocorreu pela elevada altura de ataque, o que não necessariamente indicou um adequado restabelecimento.

O mapa de taxa de risco do besouro foi semelhante ao mapa da densidade das árvores de maiores dimensões (Figura $6 \mathrm{C}$ e B), o que indicou que os locais com alta densidade de indivíduos de cedro maiores (nesse caso, os maiores tinham até a dimensão de $12 \mathrm{~cm}$ de diâmetro de coleto) foram os locais com maior probabilidade de ataque. Portanto, em florestas naturais com fins produtivos, deve-se reduzir a densidade dos indivíduos de cedro, quando chegam a essas dimensões, a fim de diminuir o risco de ataque.

O mapa de taxa de risco de $H$. grandella apresentou semelhança com o mapa de densidade. A maior taxa de incidência de ataque ocorreu em áreas com maior densidade de cedro. Isso correspondeu às áreas de menor densidade total de árvores e às áreas de clareiras, ou seja, áreas com maior incidência luminosa (Figura 6 A e D).

Estudos em áreas plantadas indicaram que a densidade de plantas de cedro não influenciou a proporção de ataque (Pérez-Salicrup \& Esquivel,

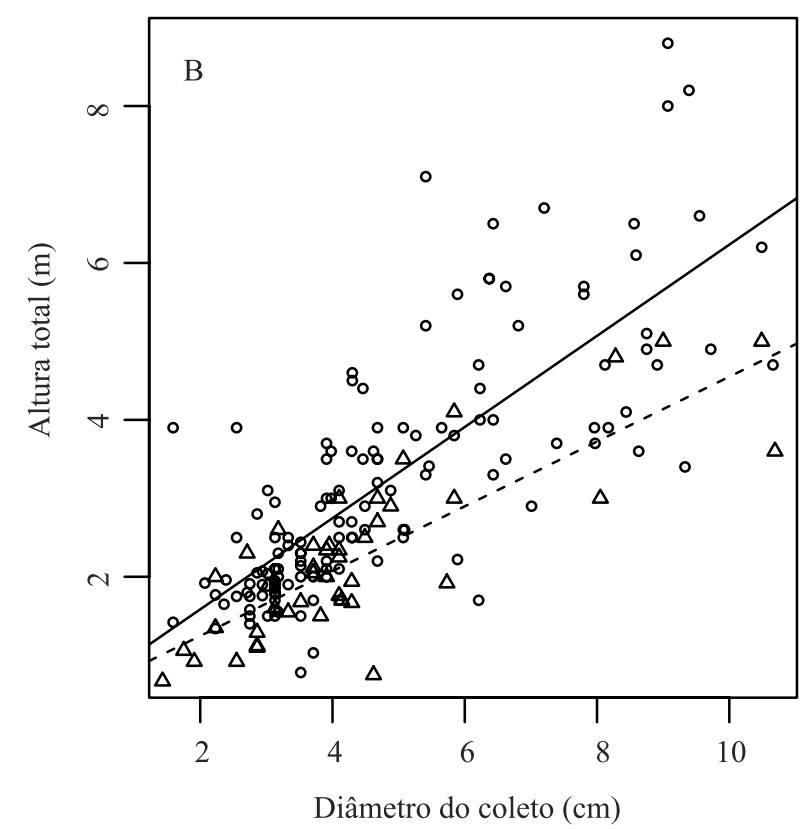

Figura 5. Relação entre altura e diâmetro do coleto de cedros saudáveis (pontos); relação hipsométrica (linha contínua) entre cedros saudáveis e cedros atacados pelo serrador (triângulos e linha tracejada) (A); e atacados pela mariposa (triângulos e linha tracejada) (B). 


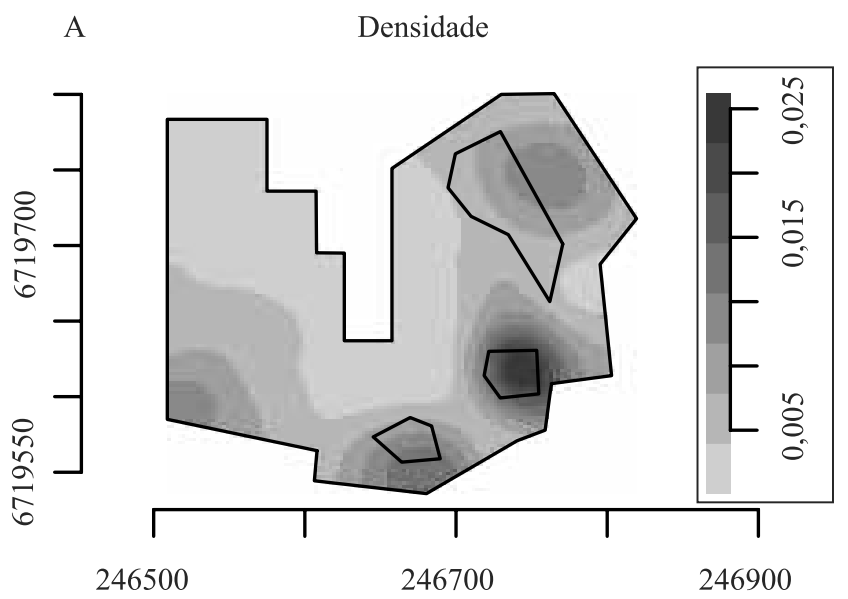

B Densidade $\mathrm{f}$ (Dcoleto)
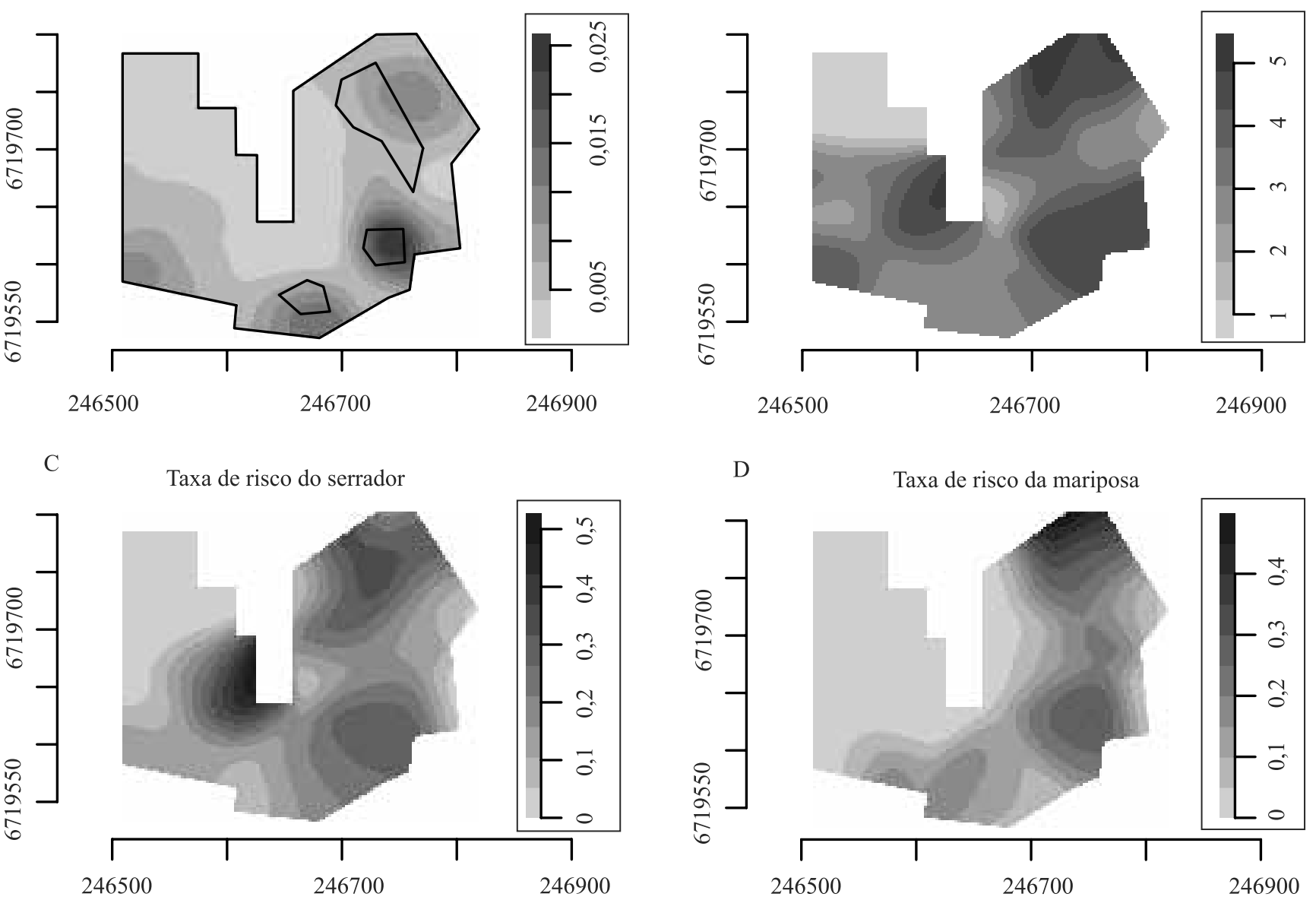

Figura 6. Mapas de intensidade de ocorrência dos cedros (densidade) (A); mapa de intensidade em função do diâmetro do coleto [Densidade $\mathrm{f}$ (Dcoleto)] (B); mapas de taxa de risco do serrador (C); e mapa de taxa de risco da mariposa (D), na região de Val Feltrina, município de Silveira Martins, RS.

2008). Assim, a maior incidência luminosa pode ser o fator preponderante na determinação da elevada taxa de incidência de ataques. Em relação a mogno, já se observou que há maior probabilidade de ataque da lagarta de $H$. grandella em plantas que estão em clareiras (Grogan et al., 2005) e em locais de maior incidência luminosa (sem sombra) (Sánchez-Soto et al., 2009). Além disso, a área com baixa densidade total de plantas (área A), que apresenta elevada taxa de risco e intensivo uso do solo, pode apresentar deficiências de suprimento de nutrientes no solo. Alguns estudos já relatam que, em condições de baixo suprimento de cálcio, há maior suscetibilidade ao ataque da mariposa (Silva et al., 2009; Silva Junior et al., 2014).

\section{Conclusões}

1. As árvores de cedro (Cedrela fissilis) com diâmetro de coleto entre 4 e $8 \mathrm{~cm}$ tem maior probabilidade de serem atacadas pelo serrador (Oncideres sp.) e, as com diâmetro de coleto entre 2 e $5 \mathrm{~cm}$ e entre 10 e $12 \mathrm{~cm}$, pela lagarta da mariposa Hypsipyla grandella.

2. Os cedros que sofreram ataque da mariposa e do serrador apresentam altura total menor, e o dano causado pelo ataque é maior à medida que aumenta a dimensão da árvore.

3. Indivíduos de cedro são mais suscetíveis ao ataque da mariposa, em áreas de clareira e de menor densidade total de árvores, e ao ataque do serrador, em áreas com elevada densidade de árvores de cedro com dimensões entre 8 e $12 \mathrm{~cm}$ de diâmetro de coleto. 


\section{Agradecimentos}

À Coordenação de Aperfeiçoamento de Pessoal de Nível Superior (Capes), pela concessão de bolsa.

\section{Referências}

ABRAHAM, J.; OPUNI-FRIMPONG, E.; WEISSBECKER, B.; SCHÜTZ, S.; ANGELI, S. Olfactory cues of mahogany trees to female Hypsipyla robusta. Bulletin of Insectology, v.67, p.21-30, 2014.

BADDELEY, A.; TURNER, R. spatstat: an R Package for analyzing spatial point patterns. Journal of Statistical Software, v.12, p.1-42, 2005.

CALIXTO, C.G.; LOPEZ, M.A.; EQUIHUA, A.; LIRA, D.E.; CETINA, V.M. Crescimiento de Cedrela odorata e incidencia de Hypsipyla grandella en respuesta al manejo nutrimental. Bosque, v.36, p.265-273, 2015. DOI: 10.4067/S0717-92002015000200012.

COSTA, E.C.; D’AVILA, M.; CANTARELli, E.B.; MURARI, A.B. Entomologia florestal. 2.ed. Santa Maria: Ed. da UFSM, 2011. 244p.

COSTA, M.S. da; FEITOSA, C.T.L.; CRUZ, S.S. da; RIBEIRO, S.B.; MORAIS, A.B.F.; OLIVEIRA, M.G. de. Crescimento do mogno em sistema silvipastoril. Revista Agroecossistemas, v.5, p.53-57, 2013.

GROGAN, J.; LANDIS, R.M.; ASHTON, M.S.; GALVÃO, J. Growth response by big-leaf mahogany (Swietenia macrophylla) advance seedling regeneration to overhead canopy release in southeast Pará, Brazil. Forest Ecology and Management, v.204, p.399-412, 2005. DOI: 10.1016/j.foreco.2004.09.013.

HILJE, L; CORNELIUS, J. ¿Es inmanejable Hypsipyla grandella como plaga forestal? Manejo Integrado de Plagas, v.61, p.1-4, 2001. (Hoja técnica, 38).

HOWARD, F.W.; MERIDA, M.A. Mahogany Shoot Borer, Hypsipyla grandella (Zeller) (Insecta: Lepidoptera: Pyralidae: Phycitinae). 2015. Available at: <https://edis.ifas.ufl.edu/pdffiles/ IN/IN61300.pdf $>$. Accessed on: 25 May 2015.

INSTITUTO BRASILEIRO DE GEOGRAFIA E ESTATÍSTICA. Mapa de vegetação Brasil. 2004. Disponível em: <ftp://ftp.ibge. gov.br/Cartas_e_Mapas/Mapas_Murais/>. Acesso em: 25 ago. 2009.

KUINCHTNER, A.; BURIOL, G.A. Clima do Estado do Rio Grande do Sul segundo a classificação climática de Köppen e Thornthwaite. Disciplinarum Scientia. Série: Ciências Exatas, v.2, p.171-182, 2001.

LEMES, P.G.;ANJOS, N. dos; CORDEIRO, G. Injúrias e oviposição de Oncideres impluviata (Germar) (Col.: Cerambycidae) em Piptadenia gonoacantha (Mart.) Macbr. Comunicata Scientiae, v.2, p.53-56, 2011.

LUNZ, A.M.; THOMAZINI, M.J.; MORAES, M.C.B.; NEVES, E.J.M.; BATISTA, T.F.C.; DEGENHARDT, J.; SOUSA, L.A. de; OHASHI, O.S. Hypsipyla grandella em mogno (Swietenia macrophylla): situação atual e perspectivas.
Pesquisa Florestal Brasileira, n.59, p.45-44, 2009. DOI: 10.4336/2009.pfb.59.45.

PENÃ-RAMÍREZ, Y.J.; GARCÍA-SHESEÑA, I.; HERNÁNDEZ-ESPINOZA, Á.; DOMÍNGUEZ-HERNÁNDEZ, A.; BARREDO-POOL, F.A.; GONZÁLEZ-RODRÍGUEZ, J.A.; ROBERT, M.L. Induction of somatic embryogenesis and plant regeneration in the tropical timber tree Spanish red cedar [Cedrela odorata L. (Meliaceae)]. Plant Cell, Tissue and Organ Culture, V.105, p.203-209, 2011.

PÉREZ-SALICRUP, D.R.; ESQUIVEL, R. Tree infection by Hypsipyla grandella in Swietenia macrophylla and Cedrela odorata (Meliaceae) in Mexico's southern Yucatan Peninsula. Forest Ecology and Management, v.255, p.324-327, 2008. DOI: 10.1016/j.foreco.2007.09.054.

PINTO, A.A.; TELES, B.R.; PENTEADO-DIAS, A.M. First report of Phanerotoma bennetti Muesebeck (Hymenoptera, Braconidae, Cheloninae) Parasitizing Hypsipyla grandella (Zeller) and Hypsipyla ferrealis Hampson (Lepidoptera, Pyralidae) in Crabwood in Brazil. Brazilian Journal of Biology, v.74, p.264265, 2014. DOI: 10.1590/1519-6984.23812.

REITZ, R.; KLEIN, R.M.; REIS, A. Projeto Madeira do Rio Grande do Sul. Porto alegre: Governo do Rio Grande do Sul, 1983. 525p.

SÁNCHEZ-SOTO, S.; DOMÍNGUEZ-DOMÍNGUEZ, M.; CORTÉS-MADRIGAL, H. Efecto de la sombra en plantas de caoba sobre la incidencia de Hypsipyla grandella Zeller y otros insectos, en tabasco, México. Universidad y Ciencia, v.25, p.225-232, 2009.

SANTOS, H.G. dos; JACOMINE, P.K.T.; ANJOS, L.H.C. dos; OLIVEIRA, V.A. de; OLIVEIRA, J.B. de; COELHO, M.R.; LUMBRERAS, J.F.; CUNHA, T.J.F. (Ed.). Sistema brasileiro de classificação de solos. 2.ed. Rio de Janeiro: Embrapa Solos, 2006. 306p.

SILVA JUNIOR, M.L. da; SOUZA JUNIOR, J.C. de; BRAGA, A.C.M.; OHASHI, O.S.; MELO, V.S. de; SILVA, G.R. da; PEDROSO, A.J.S.; VIÉGAS, I.J. de M.; SALDANHA, E.C.M. Crescimento de mogno-brasileiro e resistência a Hypsipyla grandella em função do cálcio e do boro. Revista Árvore, v.38, p.1085-1094, 2014. DOI: 10.1590/S0100-67622014000600013.

SILVA, S.A.S. da; SANTOS, M.M. de L.S.; SILVA, G.R. da; SILVA JÚNIOR, M.L. da; OHASHI, O.S.; RUIVO, M. de L.P. Efeito do cálcio no controle da Hypsipila grandella em mudas de mogno cultivadas em hidroponia. Acta Amazonica, v.39, p.273-278, 2009. DOI: 10.1590/S0044-59672009000200005.

SILVA, S.L.C. da; FACHEL, J.M.G.; KATO, S.K.; BASSANESI, S.L. Visualização dos padrões de variação da taxa de mortalidade infantil no Rio Grande do Sul, Brasil: comparação entre as abordagens bayesiana empírica e totalmente bayesiana. Cadernos de Saúde Pública, v.27, p.1423-1432, 2011. DOI: 10.1590/ S0102-311X2011000700017.

SOUZA, G.K.; PIKART, T.G.; PIKART, F.C.; ZANUNCIO, J.C. Registro de Oncideres saga (Coleoptera: Cerambycidae) em Peltophorum dubium (Leguminosae) no município de Trombudo Central, Santa Catarina, Brasil. EntomoBrasilis, v.5, p.75-77, 2012. DOI: 10.12741/ebrasilis.v5i1.150. 
THE R FOUNDATION. R: the R project for statistical computing. Vienna: The R Foundation, 2013.

WITECK NETO, L.; LINK, D.; PASINI, M.B. Cerambycidae associados a Ocotea puberula. Pesquisa Florestal Brasileira, v.33, p-455-458, 2013. DOI: 10.4336/2013.pfb.33.76.357.
YARED, J.A.G.; CARPANEZZI, A.A. Conversão da capoeira alta da Amazônia em povoamento de produção madeireira: o método do 'recru' e espécies promissoras. Belém: EMBRAPA-CPATU, 1981. 27p. (EMBRAPA-CPATU. Boletim de pesquisa, 25).

Recebido em 19 de novembro de 2014 e aprovado em 27 de agosto de 2015 